\title{
Performance on Middle School Geometry Problems with Geometry Clues Matched to Three Different Cognitive Styles
}

\section{Citation}

Anderson, Karen L., M. Beth Casey, William L. Thompson, Marie S. Burrage, Elizabeth Pezaris, and Stephen M. Kosslyn. 2008. Performance on middle school geometry problems with geometry clues matched to three different cognitive styles. Mind, Brain, and Education 2, no. 4: 188-197.

\section{Published Version}

http://dx.doi.org/10.1111/j.1751-228X.2008.00053.x

\section{Permanent link}

http://nrs.harvard.edu/urn-3:HUL.InstRepos:3153314

\section{Terms of Use}

This article was downloaded from Harvard University's DASH repository, and is made available under the terms and conditions applicable to Other Posted Material, as set forth at http:// nrs.harvard.edu/urn-3:HUL.InstRepos:dash.current.terms-of-use\#LAA

\section{Share Your Story}

The Harvard community has made this article openly available.

Please share how this access benefits you. Submit a story.

Accessibility 


\section{Performance on Middle School Geometry Problems With Geometry Clues Matched to Three Different Cognitive Styles}

Karen L. Anderson', M. Beth Casey ${ }^{2}$, William L. Thompson ${ }^{3}$, Marie S. Burrage ${ }^{3}$ Elizabeth Pezaris ${ }^{4}$, and Stephen M. Kosslyn ${ }^{3,5}$

ABSTRACT - This study investigated the relationship between 3 ability-based cognitive styles (verbal deductive, spatial imagery, and object imagery) and performance on geometry problems that provided different types of clues. The purpose was to determine whether students with a specific cognitive style outperformed other students, when the geometry problems provided clues compatible with their cognitive style. Students were identified as having a particular cognitive style when they scored equal to or above the median on the measure assessing this ability. A geometry test was developed in which each problem could be solved on the basis of verbal reasoning clues (matching verbal deductive cognitive style), mental rotation clues (matching spatial imagery cognitive style), or shape memory clues (matching object imagery cognitive style). Straightforward cognitive style-clue-compatibility relationships were not supported. Instead, for the geometry problems with either mental rotation or shape memory clues, students with a combination of both verbal and spatial cognitive styles tended to do the best. For the problems with verbal reasoning clues, students with either a verbal or a spatial cognitive style did well, with each cognitive style contributing separately to success. Thus, both spatial imagery and verbal

\footnotetext{
${ }^{1}$ Department of Education Studies, Stonehill College

${ }^{2}$ Program in Applied Developmental and Educational Psychology, Lynch School of Education, Boston College

${ }^{3}$ Department of Psychology, Harvard University

${ }^{4}$ Department of Counseling and Applied Educational Psychology, North eastern University

${ }^{5}$ Department of Neurology, Massachusetts General Hospital
}

Address correspondence to M. Beth Casey, Program in Applied Developmental and Educational Psychology, Lynch School of Education, 201 Campion Hall, Boston College, Chestnut Hill, MA 02492; e-mail: caseyb@bc.edu. deductive cognitive styles were important for solving geometry problems, whereas object imagery was not. For girls, a spatial imagery cognitive style was advantageous for geometry problem solving, regardless of type of clues provided.

Although a great deal of research has been reported on cognitive styles (Sternberg \& Grigorenko, 1997; Zhang, 2001, 2003), few studies are rooted in research on brain functioning. In recent years, understanding how the brain gives rise to information processing has increased by leaps and bounds, and such data provide enormous leverage for understanding virtually all aspects of cognition. In order to understand the nature of cognitive style and its implications for mathematics education, it is essential to situate this research within the framework of the latest theories and research in cognitive psychology and cognitive neuroscience (Kozhevnikov, 2007).

Understanding cognitive style is particularly important for mathematics problem solving because students with different cognitive styles may be trying to use very different strategies for solving the same problem (National Council of Teachers of Mathematics [NCTM], 2000). Within this context, the present study revisits the question of whether an understanding of cognitive style will enable us better to understand individual differences in solving geometry problems. However, in order to test the efficacy of different cognitive styles for solving geometry problems, we propose that it is critical to design problems in which each of the cognitive style dimensions can be used effectively to arrive at a solution. Thus, one contribution of the present study was that the geometry problems were designed with different clues provided, so that they could be solved effectively using each of the three cognitive styles. Using this approach, we were able to address the question 
of whether students with a particular ability-based cognitive style do better than other students, when geometry problems provide clues compatible with their cognitive style. This approach has theoretical significance insofar as it leads to a better understanding of the relationship between cognitive style and geometry performance. It also has practical implications for the teaching of geometry in schools because, typically, geometry is taught in school primarily through proofs, drawing on verbal, logical-deductive reasoning rather than spatial or object imagery strategies for solution (Clements \& Battista, 1992; Johnson \& Bouchard, 2005).

Cognitive style has been defined as a stable dimension that delineates consistencies in how individuals process information across tasks (Ausburn \& Ausburn, 1978; Immordino-Yang, 2007). One type of cognitive style that has been investigated extensively is the visualizer-verbalizer dimension (Richardson, 1977), which is grounded in cognitive psychology (Brooks, 1968; Paivio, 1971). Richardson defined visualizers as those individuals who prefer to process information with visual strategies, whereas he defined verbalizers as those individuals preferring to process information with verbal strategies.

Within the mathematics literature, some researchers have recognized the importance of cognitive style (e.g., Krutetskii, 1976; Presmeg, 1986a, 1986b). In general, this research focused on the simple visual-spatial/verbal dichotomy in cognitive style. Other researchers proposed a continuum called "degree of visuality," indicating level of preference for using imagery when solving problems (Moses, 1980; Presmeg, 1986a, 1986b). These conceptualizations have not proven very useful for understanding mathematical problem solving. Researchers found that students who preferred to process information by verbal-logical means often performed better on math tasks than students who preferred to process information visually (Lean \& Clements, 1981). In addition, no clear relationship was found between degree of visuality and students' levels of spatial ability (Lean \& Clements, 1981). Thus, there has been a dearth of recent research addressing this question. Although the research in mathematics relating to cognitive styles does not provide a clear picture, recent findings from cognitive neuroscience may help to clarify the issue.

Cognitive neuroscience studies provide support for the distinction between visual and verbal processing. For example, neuroimaging studies have shown that visual cortical areas are activated during visual imagery tasks (e.g., Kosslyn \& Thompson, 2003; Kosslyn, Thompson, \& Alpert, 1997; Kozhevnikov, 2007; Thompson \& Kosslyn, 2000), but not during purely verbal tasks, and vice versa for languagerelated areas (e.g., Stromswold, Caplan, Alpert, \& Rauch, 1996). However, cognitive neuroscience data do more than simply provide support for previously formulated distinctions. Researchers have found that higher level visual areas of the brain are further divided into two functionally and anatomically independent systems: one concerned with appearance of individual objects and the other with spatial relations among objects and components of objects (Kosslyn \& Koenig, 1992; Levine, Warach, \& Farah, 1985; Ungerleider $\&$ Mishkin, 1982). Both neuroscience and behavioral studies have documented that object (shape-based) and spatial types of processing rely on different mechanisms (Baddeley, 1986; Kozhevnikov, Kosslyn, \& Shephard, 2005; Logie, 1995; Ungerleider \& Mishkin, 1982). Thus, the data indicate evidence for three separate processing systems.

Consistent with these findings, researchers have recently proposed three cognitive styles (Kozhevnikov, Hegarty, \& Mayer, 2002; Kozhevnikov et al., 2005). In addition to verbalizers, different types of visualizers use imagery to process visual information in different ways. One subset of visualizers (object imagers) effectively uses mental imagery to reconstruct from memory, vivid, concrete, and detailed images of individual objects and shapes. The other subset of visualizers mentally manipulates spatial relations among objects or components of objects effectively. Such people (spatial imagers) are able to visualize complex spatial transformations, for example, by mentally rotating objects in three-dimensional space.

Because cognitive style relies in part on an individual's specific cognitive strengths (Eme \& Marquer, 1999; Katz, 1983; Kyllonen, Lohman, \& Snow, 1984), in the present study, we identified individuals as having a particular cognitive style when they showed high performance on that specific type of processing skill relative to the other students in the sample (based on whether they were equal to or above the median split). Thus, we are not assuming that cognitive styles are alternative strategies that are available to everyone but instead consider them to be ability based. One prediction is that if these three processing skills do in fact represent different cognitive styles, then the students' categorization on one cognitive style should not be related to their categorization on the other two types of cognitive styles.

We further propose that the utility of a particular type of cognitive style may depend in large part on the type of problem to be solved. No one type of cognitive style may be necessarily or universally superior to any other type. Thus, our hypothesis is that individuals will do better on those types of geometry problems that fit with person-specific, skill-based cognitive style (i.e., their pattern of processing skills). In order to provide a more accurate evaluation of the efficacy of all three cognitive styles for solving geometry problems, one must use problems where any of the three cognitive style dimensions could be used to solve the problem. The present study of geometry takes just this approach, presenting problems that can be solved via all three types of processing (verbal, object imagery, or spatial imagery). Specifically, we asked whether geometry problems are solved more effectively when the clues provided on that particular version of the problem are compatible with an individual's cognitive style. Thus, if there is a match between the clue and an individual's cognitive style, geometry performance will be higher when compared to other students lacking this 
cognitive style. For example, the cognitive style-clue-compatibility hypothesis would predict that spatial imagers should perform more effectively than object imagers or verbalizers on geometry problems that include spatial imagery clues.

Gender is another person-specific factor that may affect the match between cognitive style and geometry clue. One of the largest cognitive gender differences is the male advantage in spatial imagery, with the mean differences between males and females on mental rotation tests being close to 1 standard deviation (Halpern et al., 2007; Voyer, Voyer, \& Bryden, 1995; see, however, Wright, Thompson, Ganis, Newcombe, \& Kosslyn, 2008, for evidence that such differences may disappear with training). Furthermore, prior research has shown a stronger relationship between spatial skills and mathematics achievement for girls than for boys (Casey, Nuttall, Pezaris, $\&$ Benbow, 1995; Friedman, 1995; Tartre, 1990). Hence, more males than females may have a spatial imagery cognitive style (and gender may thus be an intervening factor) when considering spatial imagery cognitive style and geometry performance.

\section{METHODS}

\section{Participants}

We tested the complete cohort (excluding special education students) of seventh graders with parental and child permission in a suburban middle school in Massachusetts (ranging in age from 12 to 14 years). The two testing sessions occurred during social studies class (186 students: 98 males and 88 females).

\section{Procedures for Ability Measures}

The testing packet, administered in large group settings during 50-min class periods, included three assessment tasks: (a) an object imagery task testing memory for shapes, (b) a spatial imagery task requiring mental rotation, and (c) a verbal reasoning task. Investigators read instructions aloud and went through practice problems. A specified time limit was given for each task.

\section{Object Imagery Task}

To assess object imagery ability, we administered Part 1 of the Shape Memory Test from the Educational Testing Service Kit of Factor-Referenced Cognitive Tests (Ekstrom, French, \& Harman, 1976). Students were asked to memorize a series of clusters of nonrepresentational, irregular shapes (Figure 1) and given 4 min to study the page. The test page (Figure 2) consisted of 16 small clusters of shapes from the original picture. Nine were identical to a cluster of shapes on the original page ("same" items), whereas seven had slight differences in detail from one of the clusters on the original page ("different" items); 4 min were given to complete the task.
Study Page for Part 1 (4 minutes)

Study the shapes below and their position in relation to each other.

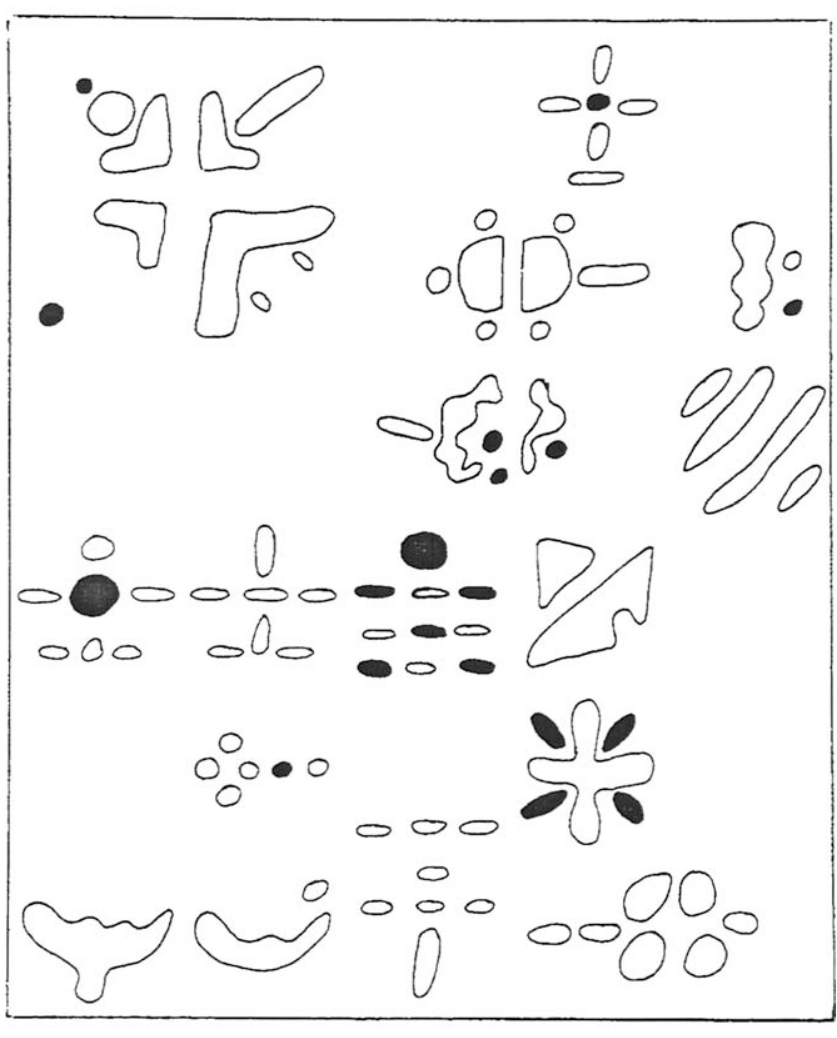

DO NOT TURN THIS PAGE UNTIL ASKEI TO DO SO.

Fig. l. The shape memory task: study box.

Spatial Imagery Task

To assess spatial imagery ability, we administered the mental rotation task based on figures designed by Shepard and Metzler (1971). The task was to compare pairs of figures presented side by side and decide whether they were "the same" (identical objects) or "different" (mirror images) (Figure 3). They were given $1 \mathrm{~min}$ per page, with 6 items on each of the three pages, for a total of 18 items ( 9 identical shapes and 9 mirror images). All drawings represented figures rotated in different orientations within three-dimensional space. An equal number of the pairs were presented at angles that differed by $20^{\circ}, 40^{\circ}$, and $60^{\circ}$ ( smallangle rotations on page 1 ); $80^{\circ}, 100^{\circ}$, and $120^{\circ}$ (medium-angle rotations on page 2 ); and $140^{\circ}, 160^{\circ}$, and $180^{\circ}$ (large-angle rotations on page 3). To hold shape differences constant across angular disparities, the same figure was used for all comparisons.

\section{Verbal Reasoning Task}

To assess verbal reasoning ability, we administered the first half (14 items) of the Word Reasoning subtest of the Wechsler Intelligence Scale for Children-Fourth Edition (WISC-IV) (Wechsler, 2004). The students were asked to use their reasoning 
Tost Page for Part 1 (4 zinutes)

For esch item, aark the $Y$ (Yes) if the shapes are the same and have the same posicion in relation to each ocher as on the study page. Mark the II (No) It they are different.
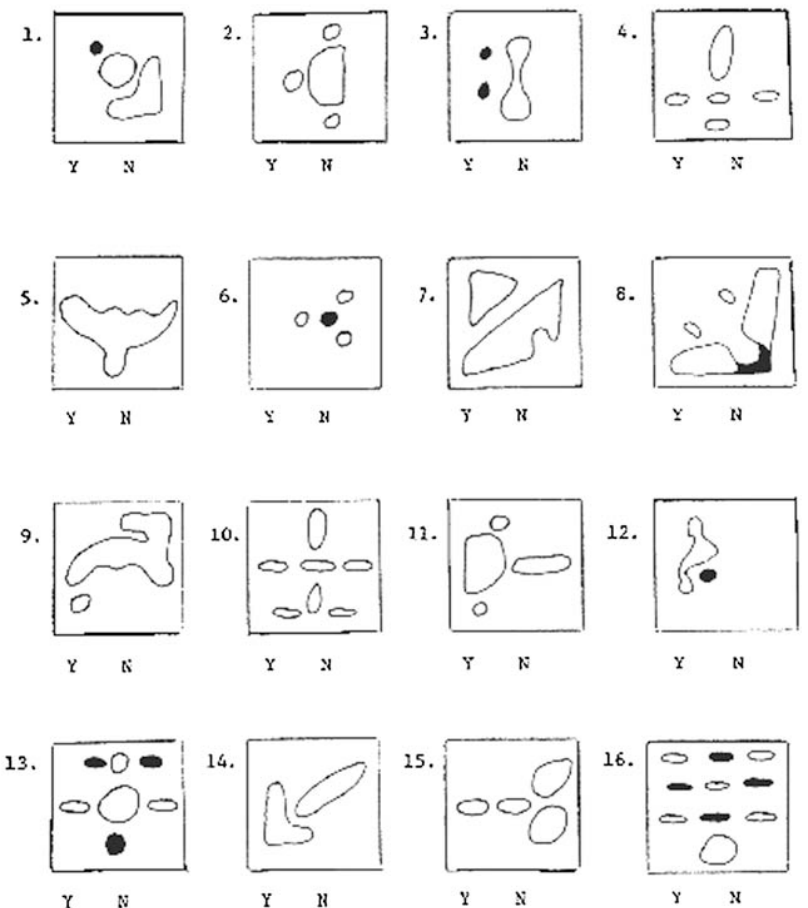

DO NOT GO ON TO TH INEXT PRKS UNTIL ASKED TO LO SO.

Fig. 2. The shape memory task: test items.

to guess what word or words the investigator was thinking of, as clues relating to this word were read aloud. Clues provided information about defining characteristics of an object, action, or concept. Participants recorded their answers on a blank line next to the clues. Students had $20 \mathrm{~s}$ to write down an answer. (Items from this verbal reasoning task are not provided as WISC-IV IQ items are not released). The test-retest reliability for this subtest is .82. The subtest factor analytic loading is .80 .

\section{Cognitive Style Categorization}

We categorized participants as "high" or "low" on the three cognitive ability measures based on a median split of the group for each measure. We labeled each student as having a particular cognitive style if his or her skill level was equal to or above the

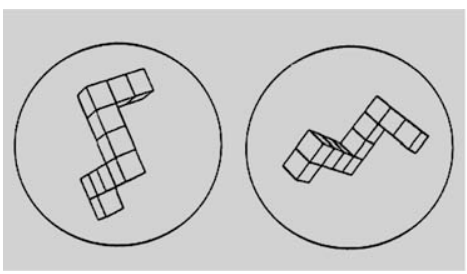

\section{Same Different}

Fig. 3. Sample item from the mental rotation task. median split on that particular measure. A particular individual could be identified as having one or more cognitive styles. (We made - and tested - the assumption that the cognitive style categories are not significantly related to one another.)

\section{The Geometry Test}

There were eight problems on the geometry test, and each was designed so it could be solved using any of three different types of clues. The items were pilot-tested with sixth graders in the same school. Students solved a range of problems in which they (a) identified the size of angles in an isosceles triangle; (b) investigated and predicted the results of putting together and taking apart two-dimensional shapes, as well as (c) putting together and taking apart angles; (d) recognized and applied slides, flips, and turns to both two-dimensional and threedimensional shapes; (e) used attributes of circles to determine the size of an embedded triangle; (f) predicted the number of triangles that would fit within a given circle; (g) compared the relative positions of elements within polygons; and (h) identified angle sizes of polygons. Thus, the task covered the extent of problems recommended for middle school by the NCTM (2003). Both regular and nonregular two-dimensional shapes (triangles, circles, and polygons) and drawings of threedimensional shapes (cubes) were included.

\section{Geometry Clues}

For each geometry problem, we designed three types of clues, each of which required students to use a different type of mental processing (compatible with one of the three cognitive styles). Because the information on the screens was presented sequentially, students were not able to solve the problems without the additional information provided by these clue screens. Individual students were assigned to only one of the three types of clues for each problem. See Figures 4 a through $4 \mathrm{e}$ for an example of the series of screens that make up one entire geometry problem; note that for this example, all participants viewed Screens $4 \mathrm{a}$ and $4 \mathrm{~b}$, but each participant would receive only one of the clue screens for each problem.

For the verbal clue screens, requiring logical, deductive reasoning (Figure 4c), participants saw a set of verbal geometry rules, definitions, or formulas plus relevant information that might be needed to solve the problem (e.g., the sizes of different angles). All the necessary information was provided on this screen, so that the students did not need to draw upon memory to solve the problem.

For the shape memory clue screens, relying on object-based imagery, the students had to both remember and mentally compare different shapes or angles. All shapes/angles were rotated to the same orientation, so that mental rotation would not be necessary. On the first shape memory clue screen, students were presented with the figure(s) from the problem screen only 


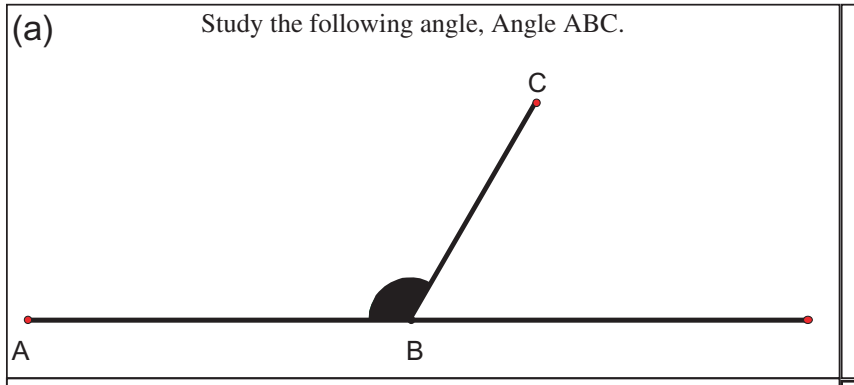

(c) Verbal Clue Screen.

Which two angles (X, Y, or Z) when added together produce an angle equal to the angle $<\mathrm{ABC}$ ?

Angle $<\mathrm{ABC}$ on the first screen is equal to $120^{\circ}$.

Rule of geometry: Two angles are supplementary when they add up to $180^{\circ}$ For example, an angle of $70^{\circ}$ is supplementary to $110^{\circ}$ because $70^{\circ}+110^{\circ}=180^{\circ}$.

Angle $\mathrm{X}$ is supplementary to $65^{\circ}$.

Angle $\mathrm{Y}$ is supplementary to $90^{\circ}$.

Angle $\mathrm{Z}$ is supplementary to $150^{\circ}$.

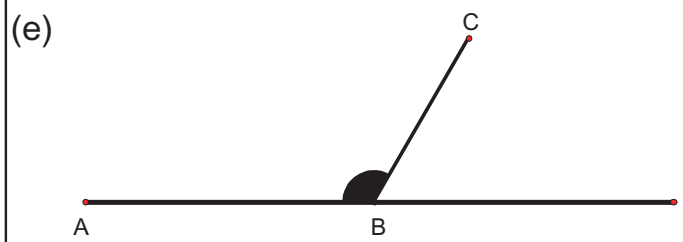

Which two angles $(\mathrm{X}, \mathrm{Y}$, or $\mathrm{Z}$ ) when added together produce an angle equal to the angle $<\mathrm{ABC}$, shown above? (b)

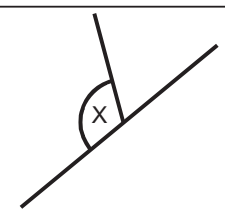

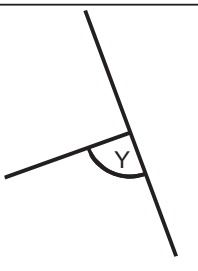

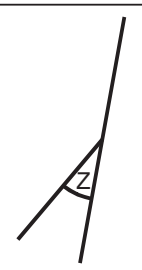

Which two angles when added together produce an angle equal to the angle $<\mathrm{ABC}$, you've just seen? DO NOT attempt to solve the problem NOW. Wait until you are given the clue in the next screen.

(d)

Shape Memory Clue Screen 1.

This is the angle from the first screen.

On the next screen you will be shown the three choice angles. You will need to determine which two of the three choice angles will form the angle below when added together.

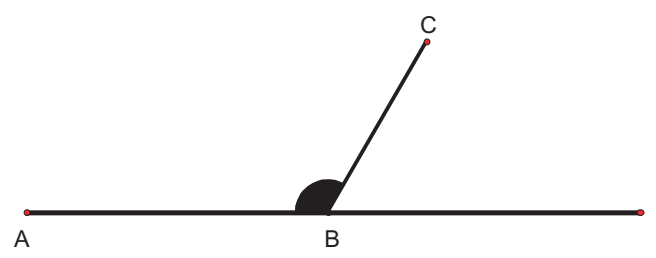

Shape Memory Clue Screen 2.

Which two angles (X, Y, or $\mathrm{Z}$ ) when added together produce an angle equal to the angle $\angle A B C$, you've just seen?

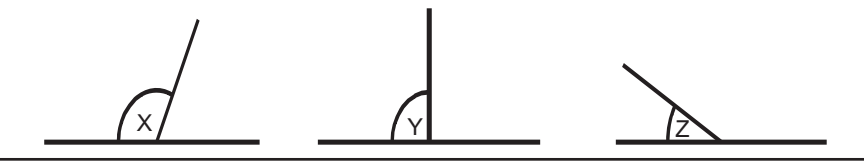

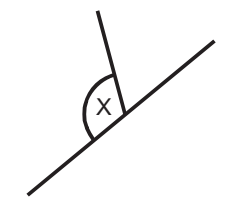
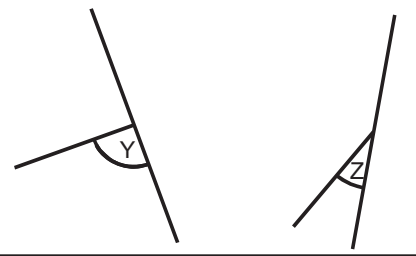

Fig. 4. Example of a geometry problem: (a) problem screen, (b) question screen, (c) clue screen for the verbal deductive clue, (d) clue screens for the shape memory clue, and (e) clue screen for the mental rotation clue.

(e.g., Figure 4d, top). Next, an intervening blank screen was presented, so that the students had to draw upon memory of the figures, and accurately visualize them, to solve the problem. Then, on a second clue screen, they received additional information needed to solve the problem (e.g., Figure 4d, bottom).

For the mental rotation clue screen, relying on spatial imagery, students were shown all the figures (from both the problem and the question screens), presented in different orientations. All the necessary information was provided on this screen, so that the students did not need to draw upon memory of the visual shapes to solve the problem. Instead, these figures had to be mentally rotated, so that they could be compared directly to one another (e.g., Figure 4e).
Procedure

We presented geometry problems using Geometer's Sketchpad ${ }^{\circledR}$ software (Key Curriculum Press, 2001). Problems were presented on a series of consecutive computer screens. Students were not allowed to view prior screens. To move from one screen to the next, students clicked an "action button" located on the screen.

Small groups of three to six students were taken to a room equipped with computers. Instructions were given, and a sample problem reviewed. Students were asked to move through the computerized set of problems, at their own pace, and to record their answers on the paper answer sheet presented in multiple-choice format. Scratch paper 
was provided. It took an average of 20 min to complete the problems.

For each item, on the first screen (the problem screen, Figure 4a), we presented a target geometric figure or set of figures. Students were asked to study them. The next screen was the question screen (Figure $4 \mathrm{~b}$ ), with another geometric figure or set of figures (related to the first screen) and a geometry question. Students were told not to attempt to solve the problem at this point as additional critical clues would be provided. Next, the clue screen with the original question repeated and the clue was provided.

For a given problem, each participant received just one of three possible types of clues. To control for order effects, we created two versions of each document, where problems were presented in reverse order of one another. Each test included four items using one clue type, alternating with four items using a different clue type. There were six versions of the test with students assigned to a version based on their relative performance on our three measures of cognitive style.

To have a range of skills on the geometry test and to have sufficient numbers of geometry problems associated with a particular type of clue, we gave students four geometry problems with clues consistent with their highest cognitive performance level and four geometry problems consistent with their lowest cognitive performance level (based on $z$ score conversion for type of ability). However, it is important to note that the predicted cognitive style-cluecompatibility hypothesis was based not upon within-student performance levels but rather on their performance relative to the group median. The difficulty with using a within-student comparison is that for some students, their highest cognitive performance levels might actually be below the median when compared to the group (thereby not allowing them to fit within the high cognitive ability group in this domain). Thus, the critical factor was whether students did better when they received clues that were compatible with their cognitive style relative to the other students - not when compared to their own performance on the other processing skill measures.

\section{RESULTS}

\section{Cognitive Style Validation}

The distribution of scores for two of the three processing skills (verbal reasoning and object imagery) was clearly bimodal. This provides a rationale for analyzing the data using median splits rather than continuous variables, thereby providing a statistical as well as a theoretical rationale for identifying participants based on these dichotomous cognitive style categories. Furthermore, we wanted to establish statistically that the high- and low-ability levels for the three types of processing were not significantly related in order to show that the cognitive styles we have characterized are in fact distinct.
We performed three separate Pearson chi-square analyses. The first analysis examined the proportion of students at each level for verbal ability and compared these scores to those on our measure of spatial imagery ability. If the abilities are distinct, then we should find that every level of spatial imagery ability is represented equally at every level of verbal ability. And in fact, the groups consisted of high verbal/high spatial imagery students $(23 \%)$ versus high verbal/low spatial imagery students $(24 \%)$ versus low verbal/high spatial imagery students $(28 \%)$ versus low verbal/low spatial imagery students $(25 \%)$; the chi-square analysis was not significant, $\chi^{2}(1)=0.33, p=.57$. Thus, there was no consistent relationship between students who were high or low scorers on the spatial imagery cognitive style measure and high or low scorers on the verbal reasoning cognitive style measure.

We performed the same analyses to compare spatial imagery and object imagery styles. The groups consisted of the high object imagery/high spatial imagery students (26\%) versus high object imagery/low spatial imagery students (30\%) versus low object imagery/high spatial imagery students (25\%) versus low object imagery/low spatial imagery students $(19 \%)$; this chi-square analysis was also not significant, $\chi^{2}(1)=$ $1.85, p=.17$.

Our final chi-square analysis in this series compared object imagery and verbal ability. The groups consisted of the high verbal/high object imagery students (26\%) versus high ver$\mathrm{bal} /$ low object imagery students (21\%) versus low verbal/high object imagery students (29\%) versus low verbal/low object imagery students (24\%); this chi-square analysis also was not significant, $\chi^{2}(1)=0.01, p=.94$.

Thus, for each of these analyses, no consistent relationship was found between the high and the low scorers on the cognitive style measures. Altogether, these three chi-square analyses suggest that cognitive style measures tap separate types of processes for this sample.

\section{Gender Comparisons}

Next, we performed a series of chi-square analyses to compare the proportion of males versus females for each of the levels of the three measures of cognitive style. We did not find a significant gender relationship for the object imagery test or the verbal reasoning test. However, as expected, we did find that there were more boys (65\%) than girls (35\%) who had high spatial imagery ability (i.e., scored above the median for the group), $\chi^{2}(1)=16.79, p<.001$.

\section{Effects of Different Geometry Clues}

We next performed three analyses on the scores from the geometry problems based on the specific types of clues provided. 
Geometry Problems With Mental Rotation Clues

We first analyzed performance on the mental rotation clue geometry problems as the dependent variable using a $2 \times 2 \times 2 \times$ 2 analysis of variance (ANOVA) to examine the effects of verbal reasoning ability level (high vs. low), mental rotation ability level (high vs. low), shape memory ability level (high vs. low), and gender (male vs. female). We found a significant interaction between spatial imagery ability level and verbal reasoning ability level, $F(1,110)=4.17, p=.043$, and a significant interaction between gender and spatial imagery ability, $F(1,110)=4.84, p=.030$. No other main effects or interactions were significant.

For the Spatial Imagery Ability $\times$ Verbal Reasoning Ability interaction, we performed simple effects analyses using the Bonferroni test. We failed to find significant differences between high and low spatial imagery levels for the low verbal reasoning group. However, among the high verbal reasoning students, the high spatial imagery students $(M=3.04$, $S D=1.0, N=26$ ) performed significantly better on the mental rotation clue geometry items than did the low spatial imagery students $(M=2.37, S D=1.17, N=35), F(1,110)=6.01, p=.016$ (Figure 5). The Cohen's $d$ indicator of effect size was .67. This effect is large in size according to Cohen's power analysis standards, the conventional criteria in the literature.

For the Gender × Spatial Imagery Ability interaction, we performed simple effects analyses for girls and boys separately using the Bonferroni test. As expected, girls with high spatial imagery ability $(\mathrm{M}=2.65, \mathrm{SD}=1.23, \mathrm{~N}=23)$ performed significantly better than girls with low spatial imagery ability $(M=$ $2.03, S D=0.92, N=38$ ) on the mental rotation geometry items, $F(1,110)=6.85, p=.01$. The effect size for the girls was .67. This is a large effect size. No significant differences were found for boys (Figure 6).

Geometry Problems With Shape Memory Clues

Using the same analyses on the shape memory clue items, we found the identical pattern of results as for the mental rotation clue items. There was a significant interaction between spatial imagery ability and verbal reasoning ability, $F(1,93)=4.05$, $p=.047$, and a significant interaction between gender and spatial imagery ability, $F(1,93)=4.42, p=.038$. No other main effects or interactions were significant. These results were surprising: Spatial imagery ability, not object imagery ability, predicted performance on the shape memory clue geometry items.

Again, for the students with low verbal reasoning ability, simple effects analyses on the shape memory clue items failed to show significant differences between high and low spatial imagery levels, whereas, among the high verbal reasoning group, high spatial imagery students $(M=2.86, S D=0.94, N=35)$ did in fact perform significantly better on the shape memory clue geometry items than the low spatial imagery students $(M=2.2$, $S D=1.00, N=20), F(1,93)=9.55, p=.003$ (Figure 7). The Cohen's $d$ indicator of effect size was .70. This effect is large in size.

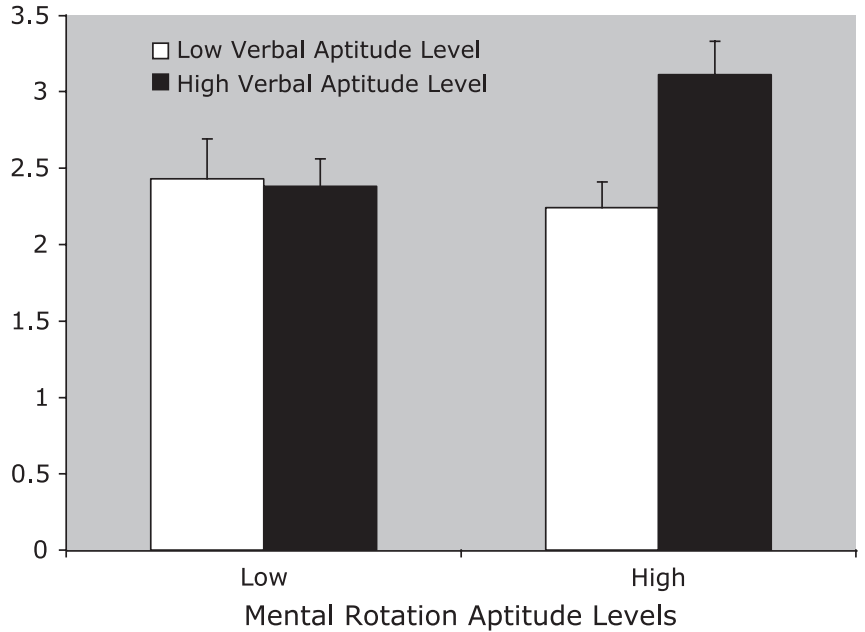

Fig. 5. Mean scores on the geometry items with mental rotation clues as a function of mental rotation and verbal aptitude levels.

To examine the Gender × Spatial Imagery Ability interaction, simple effects analyses were performed separately for girls and for boys. Girls with high spatial imagery ability $(M=2.94$, $S D=0.93, N=16$ ) performed significantly better than girls with low spatial imagery ability $(M=2.20, S D=0.90, N=35)$ on the shape memory clue geometry items, $F(1,93)=5.91$, $p=.017$. The effect size for the girls was .82 . No significant differences were found for boys (Figure 8).

\section{Geometry Problems With Verbal Deductive Reasoning Clues}

We performed the same omnibus ANOVA for the condition where verbal deductive reasoning clues were provided and found a significant main effect of high/low verbal reasoning ability, $F(1,101)=15.41, p<.001$, and a significant main effect

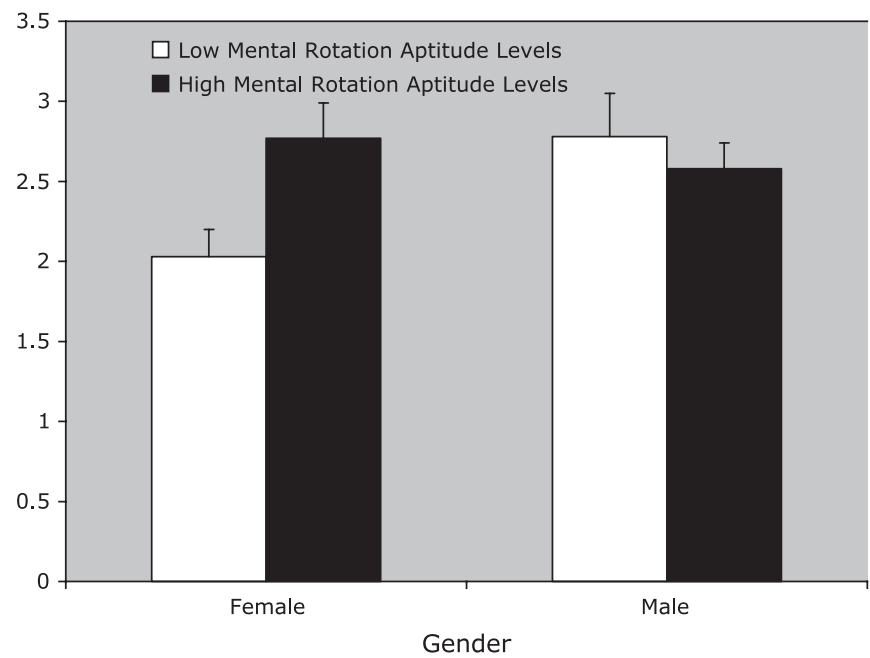

Fig. 6. Mean scores on the geometry items with mental rotation clues as a function of gender and mental rotation aptitude levels. 


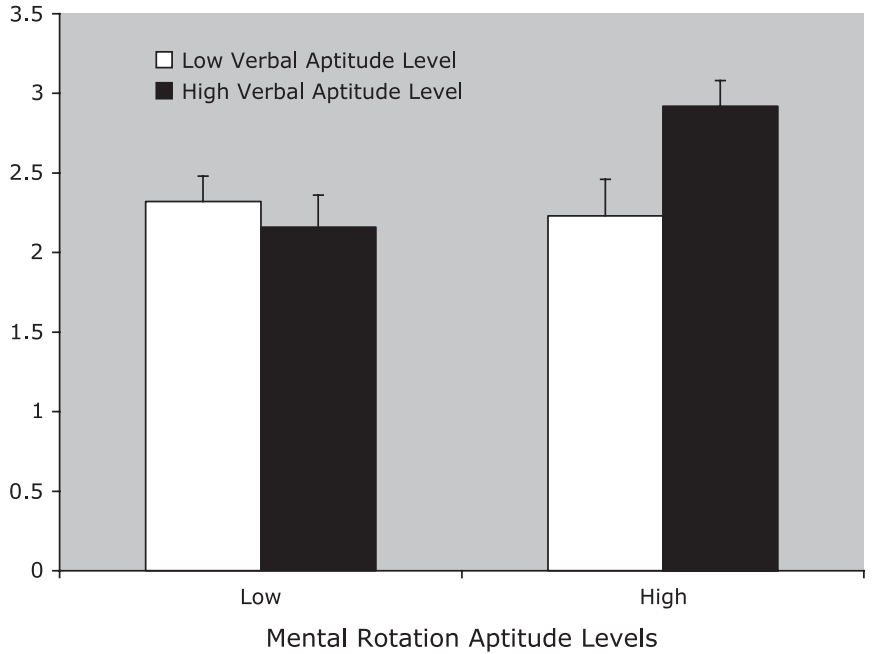

Fig. 7. Mean scores on the geometry items with shape memory clues as a function of verbal and mental rotation aptitude levels.

of high/low spatial imagery ability, $F(1,101)=12.98, p<.001$. As predicted, students who had high verbal reasoning ability scored significantly higher on the deductive reasoning clue geometry items $(M=2.52, S D=0.95, N=60)$ than did those who had low verbal reasoning ability $(M=1.82, S D$ $=1.09, \mathrm{~N}=57$ ). The Cohen's $d$ indicator of effect size was .74 . Interestingly, students with high spatial imagery ability also scored significantly higher $(M=2.47, S D=1.04, N=57)$ on the geometry items with verbal deductive reasoning clues than those who scored low on spatial imagery ability $(M=1.90, S D=1.04, N=60)$. The Cohen's $d$ indicator of effect size was .55. No other main effects or interactions were significant.

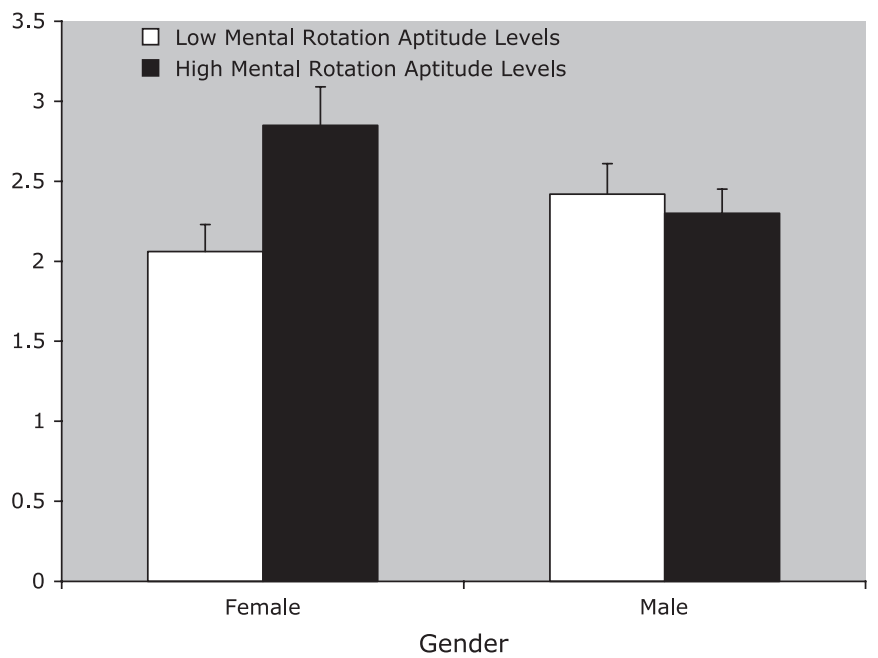

Fig. 8. Mean scores on the geometry items with shape memory clues as a function of gender and mental rotation aptitude levels.

\section{DISCUSSION}

We found support for the view that the three cognitive styles are independent of one another for this seventh-grade sample. Consistent with recent neuropsychological findings (Kozhevnikov et al., 2002, 2005), the simple distinction between verbalizers and visualizers is not sufficient; there do appear to be three types of cognitive styles-a verbal style as well as two types of visual cognitive styles.

However, we did not find strong support for the cognitive style-clue-compatibility hypothesis. Rather, both spatial imagers and verbalizers were found to score highly on the geometry items across the clues. Although object imagery may be an effective cognitive style for solving other types of problems, this cognitive style did not help students to perform any of the geometry problems-even when we gave the students shape memory clues. These findings suggest that a person who is very adept at constructing vivid, detailed images of individual objects will not necessarily be good at solving geometry problems. Our findings further buttress previous research showing that spatial imagery rather than object imagery is related to success in mathematics problem solving (Hegarty \& Kozhevnikov, 1999; Presmeg, 1986a, 1986b). These results are also consistent with the recent finding that scientists and engineers excel at spatial imagery, whereas visual artists excel in object imagery and prefer object-based strategies (Kozhevnikov et al., 2005). Note that the NCTM (2000) has not made the distinction between object and spatial imagery but instead includes both in what they designate "spatial sense." The conclusion that good imagery skills are related to mathematics performance needs to be restated as good spatial imagery skills are related to successful mathematics performance. This distinction has important implications for the teaching of mathematics.

One factor may help to explain why the object imagers did not do well on the geometry problems with the shape memory clues. The object imagery skill assessed in the present study draws on short-term memory ability (specifically, the ability to retain a detailed image of the objects in an array); it does not require using working memory to integrate and manipulate information that is simultaneously being held in mind. In contrast, all the geometry problems-even those with the shape memory clues-required the use of working memory. For example, for the geometry problem with the shape memory clue in Figure 4d, not only did the students have to remember the angles to solve the geometry problem (as presented in the clue screen), but they also had to mentally move these images and combine them, thereby drawing on their working memory skills.

There is both behavioral and neuroimaging evidence for two working memory systems (Baddeley, 1986; Brooks, 1968; Jonides \& Smith, 1997), one that processes spatial information and one that processes verbal information. Thus, one 
interpretation of the present results might be that spatial imagers depend on their spatial working memory skills, whereas verbalizers depend on their verbal working memory skills-and that both types of working memory skills are involved in geometry problem solving.

We found that for the geometry problems with either spatial or object imagery clues, the students with a combination of both verbal and spatial cognitive styles tended to do the best. For the problems with verbal clues, a different pattern emerged-each cognitive style appeared to contribute separately to success. This suggests that the students who excelled at spatial imagery could use their spatial skills to do well on problems in which verbal clues were provided. For the verbal clues provided in Figure 4c, for example, perhaps the spatial imagers might have been able to use their spatial imagery at the same time they were reading the text. If they were able to generate and mentally combine images of the angles described verbally in the text, this would have provided them with useful additional information when solving the verbal clue problems. In contrast, the verbalizers may have bypassed their spatial imagery system altogether and instead simply used their effective verbal skills to reason logically about the solution to the problem.

There was one group of students in the study whose performance was most strongly influenced by high spatial ability - the girls. This is consistent with prior research showing a stronger relationship between spatial skills and mathematics achievement for girls than for boys (Casey et al., 1995; Friedman, 1995; Tartre, 1990). A contribution of the present research is to show that the small subgroup of high spatial girls (consisting of only $35 \%$ of the females) excelled over the low spatial girls across all three types of geometry problems-independent of type of clue provided. These findings reinforce the view that girls as a group need assistance in acquiring more effective spatial imagery skills. A recent study of gender differences in spatial ability (Kaufman, 2007) indicates that one route to improving spatial skills in females may be via developing their spatial working memory. Kaufman found substantial gender differences on spatial working memory tasks but no significant gender differences on verbal working memory tasks. Furthermore, spatial working memory skills mediated the relationship between gender and spatial ability, indicating a key connection between these spatial processes.

Gender research has been dominated by investigations of attitudinal and social factors rather than academic/cognitive skills (National Science Foundation, 2004). We suggest, however, that increasing spatial skills may in fact indirectly lead to greater math confidence among girls, thereby enabling them to use spatial as well as verbal strategies when tackling nonstandard problems on achievement tests-the types of items that girls find most difficult (Casey, Nuttall, \& Pezaris, 1997; Gallagher et al., 2000).
In conclusion, although the present findings do not provide evidence for a straightforward cognitive style-geometry clue relationship, the results do indicate the power of both spatial imagery and verbal reasoning cognitive styles for solving geometry problems-regardless of what types of clues are provided. Both spatial and verbal reasoning skills have been acknowledged as important for mathematics problem solving by math educators at the national level (NCTM, 2000). Nevertheless, the critical role of spatial imagery as a route to success for those students who excel at this processing style has not been incorporated into the teaching practices that are actually implemented within many math classrooms (Clements \& Battista, 1992; Johnson $\&$ Bouchard, 2005).

Acknowledgments-This research was supported in part by a grant from the National Science Foundation, Research on Learning and Education, Grant Number REC-0411725, S.M.K., Principal Investigator. Any opinions, findings, and conclusions or recommendations expressed in this article are those of the authors and do not necessarily reflect the views of the National Science Foundation. We would like to thank Michael Egan, Holly Schindler, and Susan Kirst for data collection and Michael Egan for programming and useful comments. We also thank the suburban school system near Boston, MA, for allowing research to be conducted at their middle school.

\section{REFERENCES}

Ausburn, L. J., \& Ausburn, F. B. (1978). Cognitive styles: Some information and implications for instructional design. Educational Communications and Technology Journal, 26, 337-354.

Baddeley, A. (1986). Working memory. Oxford, UK: Clarendon Press.

Brooks, L. E. (1968). Spatial and verbal components of the act of recall. Canadian Journal of Psychology, 22, 349-368.

Casey, M. B., Nuttall, R., Pezaris, E., \& Benbow, C. P. (1995). The influence of spatial ability on gender differences in math college entrance test scores across diverse samples. Developmental Psychology, 31, 697-705.

Casey, M. B., Nuttall, R. L., \& Pezaris, E. (1997). Mediators of gender differences in mathematics college entrance test scores: A comparison of spatial skills with internalized beliefs and anxieties. Developmental Psychology, 33, 669-680.

Clements, D. H., \& Battista, M. T. (1992). Geometry and spatial reasoning. In D. A. Grouws (Ed.), Handbook of research on mathematics teaching and learning (pp. 420-464). New York: National Council of Teachers of Mathematics/Macmillan.

Ekstrom, R. B., French, J. W., \& Harman, H. H. (1976). Manual for kit of factor referenced cognitive tests. Princeton, NJ: Educational Testing Service.

Eme, P. E., \& Marquer, J. (1999). Individual strategies in a spatial task and how they relate to aptitudes. European Journal of Psychology of Education, 14, 89-108.

Friedman, L. (1995). The space factor in mathematics: Gender differences. Review of Educational Research, 65, 22-50. 
Gallagher, A. M., De Lisi, R., Holst, P. C., McGillicuddy-De Lisi, A. V., Morely, M., \& Calahan, C. (2000). Gender differences in advanced mathematical problem solving. Journal of Experimental Child Psychology, 75, 165-191.

Halpern, D. F., Benbow, C. P., Geary, D. C., Gur, R. C., Hyde, J. S., $\&$ Gernsbacher, M. A. (2007). The science of sex differences in science and mathematics. Psychological Science, 8, 1-51.

Hegarty, M., \& Kozhevnikov, M. (1999). Types of visual-spatial representations and mathematical problem solving. Journal of Educational Psychology, 91, 684-689.

Immordino-Yang, M. H. (2007). A tale of two cases: Lessons for education from the study of two boys living with half their brains. Mind, Brain, and Education, 1, 66-83.

Johnson, W., \& Bouchard, T. J. (2005). The structure of human intelligence: It's verbal, perceptual, and image rotation (VPR), not fluid and crystallized. Intelligence, 33, 393-416.

Jonides, J., \& Smith, E. E. (1997). Working memory: A view from neuroimaging. Cognitive Psychology, 33, 5-42.

Katz, A. L. (1983). What does it mean to be a high imager? In J. C. Yuille (Ed.), Imagery, memory, and cognition (pp. 39-64). Hillsdale, NJ: Erlbaum.

Kaufman, S. B. (2007). Sex differences in mental rotation and spatial visualization ability: Can they be accounted for by differences in spatial working memory. Intelligence, 35, 211-223.

Key Curriculum Press. (2001). The geometer's sketchpad: Dynamic geometry software for exploring mathematics (Version 4) [Computer software]. Emeryville, CA: Author.

Kosslyn, S. M., \& Koenig, O. (1992). Wet mind: The new cognitive neuroscience. New York: Free Press.

Kosslyn, S. M., \& Thompson, W. L. (2003). When is early visual cortex activated during visual mental imagery? Psychological Bulletin, 129, 723-746.

Kosslyn, S. M., Thompson, W. L., \& Alpert, N. M. (1997). Neural systems shared by visual imagery and visual perception: A positron emission tomography study. Neuroimage, 6, 320-334.

Kozhevnikov, M. (2007). Cognitive styles in the context of modern psychology: Towards an integrated framework of cognitive style. Psychological Bulletin, 133, 464-481.

Kozhevnikov, M., Hegarty, M., \& Mayer, R. E. (2002). Revising the visualizer/verbalizer dimension: Evidence for two types of visualizers. Cognition $\&$ Instruction, 20, 47-77.

Kozhevnikov, M., Kosslyn, S. M., \& Shephard, J. M. (2005). Spatial versus object visualizers: A new characterization of visual cognitive style. Memory and Cognition, 33, 710-726.

Krutetskii, V. A. (1976). The psychology of mathematical abilities in schoolchildren. Chicago: University of Chicago Press.

Kyllonen, P., Lohman, D. F., \& Snow, R. (1984). Effects of aptitudes, strategy training, and task facets on spatial task performance. Journal of Educational Psychology, 76, 130-145.

Lean, C., \& Clements, M. A. (1981). Spatial ability, visual imagery, and mathematical performance. Educational Studies in Mathematics, 12, 267-299.
Levine, D. N., Warach, J., \& Farah, M. J. (1985). Two visual systems in mental imagery: Dissociation of "what" and "where" in imagery disorders due to bilateral posterior cerebral lesions. Neurology, 35, 1010-1018.

Logie, R. H. (1995). Visuo-spatial working memory. Hillsdale, NJ: Erlbaum.

Moses, B. E. (1980, April). The relationship between visual thinking tasks and problem solving performance. Paper presented at the annual meeting of the American Education Research Association, Boston.

National Council of Teachers of Mathematics. (2000). Principles and standards for school mathematics. Reston, VA: Author.

National Council of Teachers of Mathematics. (2003). Navigating through geometry in grades 6-8. Reston, VA: Author.

National Science Foundation. (2004). New formulas for America's workforce: Girls in science and engineering. Arlington, VA: Author.

Paivio, A. (1971). Imagery and verbal processes. New York: Holt, Rinehart \&e Winston.

Presmeg, N. C. (1986a). Visualization and mathematical giftedness. Educational Studies in Mathematics, 17, 297-311.

Presmeg, N. C. (1986b). Visualization in high school mathematics. For the Learning of Mathematics, 63, 42-46.

Richardson, A. (1977). Verbalizer-visualizer: A cognitive style dimension. Journal of Mental Imagery, 1, 109-125.

Shepard, R. N., \& Metzler, J. (1971). Mental rotation of threedimensional objects. Science, 171, 701-703.

Sternberg, R. J., \& Grigorenko, E. L. (1997). Are cognitive styles still in style? American Psychologist, 52, 700-712.

Stromswold, K., Caplan, D., Alpert, N., \& Rauch, S. L. (1996). Localization of syntactic comprehension by positron emission tomography. Brain $\approx$ Language, 53, 452-473.

Tartre, L. A. (1990). Spatial skills, gender and mathematics. In E. Fennema \& G. Leder (Eds.), Mathematics and gender (pp. 2759). New York: Teachers' College Press.

Thompson, W. L., \& Kosslyn, S. M. (2000). Neural systems activated during visual mental imagery: A review and meta-analyses. In A. W. Toga \& J. C. Mazziotta (Eds.), Brain mapping II: The systems (pp. 535-560). San Diego, CA: Academic Press.

Ungerleider, L. G., \& Mishkin, M. (1982). Two cortical visual systems. In D. J. Ingle, M. A. Goodale, \& R. J. W. Mansfield (Eds.), Analysis of visual behavior (pp. 549-586). Cambridge, MA: MIT Press.

Voyer, D., Voyer, S., \& Bryden, M. P. (1995). Magnitude of sex differences in spatial abilities: A meta-analysis and consideration of critical variables. Psychological Bulletin, 117, 250-270.

Wechsler, D. (2004). The Wechsler intelligence scale for children (4th ed.). San Antonio, TX: The Psychological Corporation.

Wright, R., Thompson, W. L., Ganis, G., Newcombe, N. S., \& Kosslyn, S. M. (2008). Training generalized spatial skills. Psychonomic Bulletin \& Review, 15, 763-771.

Zhang, L. F. (2001). Do thinking styles contribute to academic achievement beyond self-rated abilities? Journal of Psychology, 135, 621-637.

Zhang, L. F. (2003). Contributions of thinking styles to critical thinking dispositions. Journal of Psychology, 137, 517-544. 